\title{
水溶性アゾ染料イオンの水-有機溶媒混合媒体中における 光吸収変化とエタノールの吸光光度定量への応用
}

\author{
本水 昌二 ${ }^{\circledR}$, 細井 康宏, 大島 光子* \\ (1989 年 11 月 22 日受理)
}

3 種類の水溶性アゾ染料 (陰イオン染料と 2 種類の陽イオン染料) の光吸収変化を水-アルコール混 合溶媒中で調べた，最も大きな光吸収変化を示す染料はメチルオレンジ系染料であり，アルコール含量 の増加と共に, 吸収極大波長はブルーシフトし, 短波長測の吸光度が増大する. なかでも, 疎水性の大 きい基をもつブチルオレンジが最も鋭敏な吸光度変化を示す.この吸収変化は, 染料イオンの周りの微 細環境が親水性場から踈水性場へ変化することによるものであり, 親水性場では次式の (A）の極限構 造をとりやすく，疎水性場では（B）の構造をとりやすいためと考えられる.<smiles>[R19]N=C1C=CC(=NNc2ccc(S(=O)(=O)[O-])cc2)C=C1</smiles>

(A)<smiles>[R]Nc1ccc(N=Nc2ccc(S(=O)(=O)O)cc2)cc1</smiles>

分析的応用としては, 長波長側の吸光度減少, 短波長側の吸光度増加を利用すればアルコールの定量が 可能である. プロピルオレンジを用い， $420 \mathrm{~nm}$ の吸光度の増加を利用するエタノールの定量法が FIA 法へ応用された.

\section{1 緒言}

染料の周りの微細環境変化により, 光吸収が大きく影 響されることがある。特に親水性環境と疎水性環境の違 いは蛍光スペクトルや電子スペクトルにおける波長シフ ト, 強度の増減となって現れる。例えば, メチルオレン ジがアルブミン, ポリエチレンイミン1), 及び $\alpha$-シクロ デキストリンに取り込まれると短波長シフトする2). 又, 第四級アンモニウムイオンとのイオン会合体として クロロホルムなどの有機溶媒に抽出されたメチルオレン 棌の吸収極大波長は水溶液中よりも短波長シフトする. これらはいすれれも, 染料の周りの環境が親水性場から疎 水性場へ変化したことによるものと解釈される.

本報では, 染料イオンの周りの場の変化を分析に応用 することを考え，水一アルコール類混合溶媒中における アゾ染料の光吸収変化について検討した. その結果, メ チルオレンジ系の染料, 中でもプロピルオレンジがエ夕 ソールの吸光光度定量法に適しており, FIA への適用 可能であった。 なお，染料の光吸収変化を利用するア 凡コールの吸光光度定量については，山本らによる， ラ

\footnotetext{
* 岡山大学理学部 : 700 岡山県岡山市津島中 3-1-1
}

クトン型ローダミン B の有機溶媒溶液をアルコール水 溶液と振り混ぜることによる発色を利用する酒類中アル コールの定量法がある ${ }^{3)}$. 又, 著者らによる, Triton X-100 存在下でテトラブロモフェノールフタレインエ チルエステルの酸型を用いる水溶液法が報告されてい る4).これらの 2 法はアルコールの存在下で解離型の吸 収を示すことを利用するものであり，本報の光吸収変化 の原理とは異なるものである.

$$
2 \text { 実験 }
$$

\section{$2 \cdot 1$ 装}

分光光度計: 吸収スペクトルの測定には島津ダブル ビーム自記分光光度計 UV-300を, 吸光度の測定には 日立 139 型分光光度計を用いた。吸収セルはすべて光 路長 $10 \mathrm{~mm}$ のものを用いた。

FIA 装置 : Fig. 1 にフローダイヤグラムを示す. 流路 は内径 $0.5 \mathrm{~mm}$ の PTFE (ポリテトラフルオロエチレ ン）チューブと樹脂製コネクター類を用いて構成した. ポンプはダブルプランジャ一型マイクロポンプ (サヌキ 工業製，DM2M-1026 型）を用い，送液は $0.8 \mathrm{ml}$ $\min ^{-1}$ で行った. 検出器は $8 \mu \mathrm{l}$ のフローセル付き可視 分光検出器 (相馬光学製, S-3250 型) を用い, 記録計 


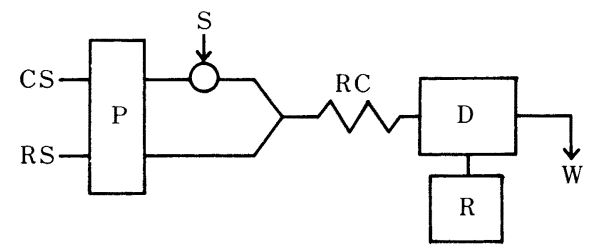

Fig. 1 Flow diagram for alcohol determination CS : carrier $\left(\mathrm{H}_{2} \mathrm{O}\right)$; $\mathrm{RS}$ : reagent solution $(2 \times$ $10^{-5} \mathrm{M} \mathrm{PO}, 40 \%(\mathrm{v} / \mathrm{v})$ ethanol, $\left.\mathrm{pH} 6.8\right) ; \mathrm{P}$ : pump $(0.8 \mathrm{ml} / \mathrm{min}) ; \mathrm{S}$ : sample $(200 \mu \mathrm{l}) ; \mathrm{RC}$ : reaction coil $(0.5 \mathrm{~mm} \times 3 \mathrm{~m}) ; \mathrm{D}$ : detector $(420$ $\mathrm{nm})$; R : recorder; $\mathrm{W}$ : waste

（東亜電波工業製，FBR-251A）で吸光度変化を記録し た。

\section{$2 \cdot 2$ 試 薬}

水溶性アゾ染料: メチルオレンジ系陰イオン染料 4 種 (Type I), N-アルキルピリジニウム系イオン染料 3 種（Type II）及びトリメチルアンモニウム系陽イオン 染料 2 種（Type III）を用いた. いずれも合成したもの であり, Fig. 2 に構造式を示した.

Type I の試薬は既報 ${ }^{5) 6)}$ と同様にFieser の著書の方 法7゙準じて合成し，ナトリウム塩として得た. Type II の試薬は既報 ${ }^{8)}$ と同様に合成した。精製したヨウ化物 の水溶液を陰イオン交換カラム $(\mathrm{Cl})$ に通すことにより 塩化物に変えた.

Type III の試薬も既報 ${ }^{9)}$ と同様に合成したものであ る. いずれも水溶液として調製した。

アルコール: 和光純薬工業製特級メタノール, エ夕 ノール, 1-プロパノール, 2-プロパノール, 1-ブタノー ル，2-メチル-2-プロパノール（t-ブタノール）をそのま ま用いた。

緩衝液：リン酸緩衝液（1 M) を用いた.

FIA 用試薬溶液 : $2 \times 10^{-4}$ M PO 及び $40 \%(v / v)$ 工 タノールを含む pH 6.7 の水溶液を用いた。この溶液組 成はバッチ法の濃度の 2 倍である.

その他の試薬もすべて市販特級品を用いた。

\section{$2 \cdot 3$ 実験操作}

2・3・1 標準操作 $25 \mathrm{ml}$ のメスフラスコに染料イ オン溶液を適量取り, リン酸緩衝液（1 M) $1 \mathrm{ml}$ を加え る.これにアルコール又は有機溶媒を含む試料水溶液を 加えた後, 蒸留水を標線まで加え, 混合後, 吸光度を測
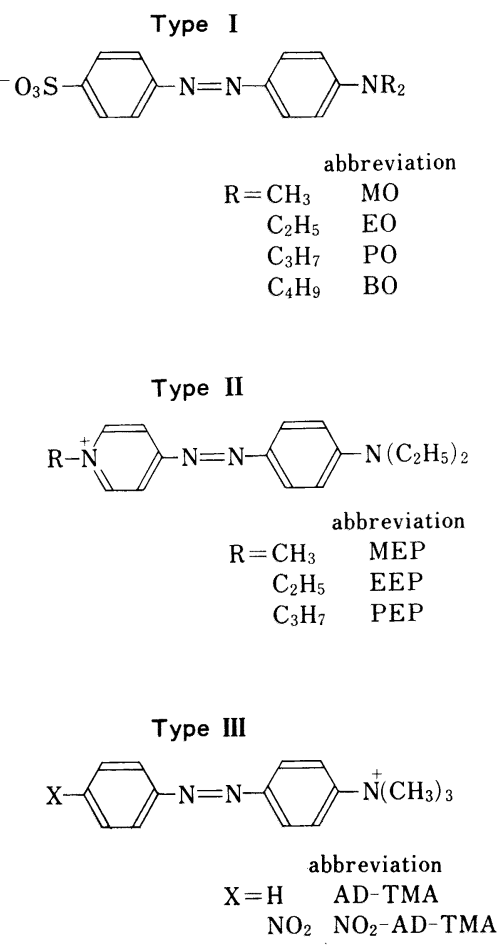

Fig. 2 Azo dye ions examined

定する.

2・3・2 エタノール定量操作（バッチ式マニュアル 法） $25 \mathrm{ml}$ のメスフラスコに試料溶液を取り，これ にエタノールを含む試料水, $5 \times 10^{-4} \mathrm{M}$ プロピルオレ ンジ水溶液 $1 \mathrm{ml}, \mathrm{pH} 6.7$ 緩衝液 $(1 \mathrm{M}) 1 \mathrm{ml}$ を加え, 蒸留水で標線に合わせる. $420 \mathrm{~nm}$ の吸光度を測定す る.

2・3・3 FIA によるアルコールの定量 Fig. 1 に 示す FIA 装置を用い, 試料溶液を注入バルブにてキャ リヤー流れに注入する。あらかじめ作成したピーク高さ を用いた検量線から含量を求める.

\section{3 結果及び考察}

\section{$3 \cdot 1$ 吸収スペクトル}

$2 \cdot 3 \cdot 1$ の標準操作法により得られたエタノールを含む 溶液の吸収スペクトルの例を Fig. 3 に示す. Type I, II ではアルコール含量の増加と共に吸収極大波長は短波長 側にシフトし，その程度は Type I のほうが大きい。 Type III では吸収極大波長はほとんど変わらず, 吸収 のみが強くなっている. 
Fig. 4 にはエ夕ノール含量と吸光度の変化の関係を示 している. Type I では吸光度の増加する $420 \mathrm{~nm}$, Type
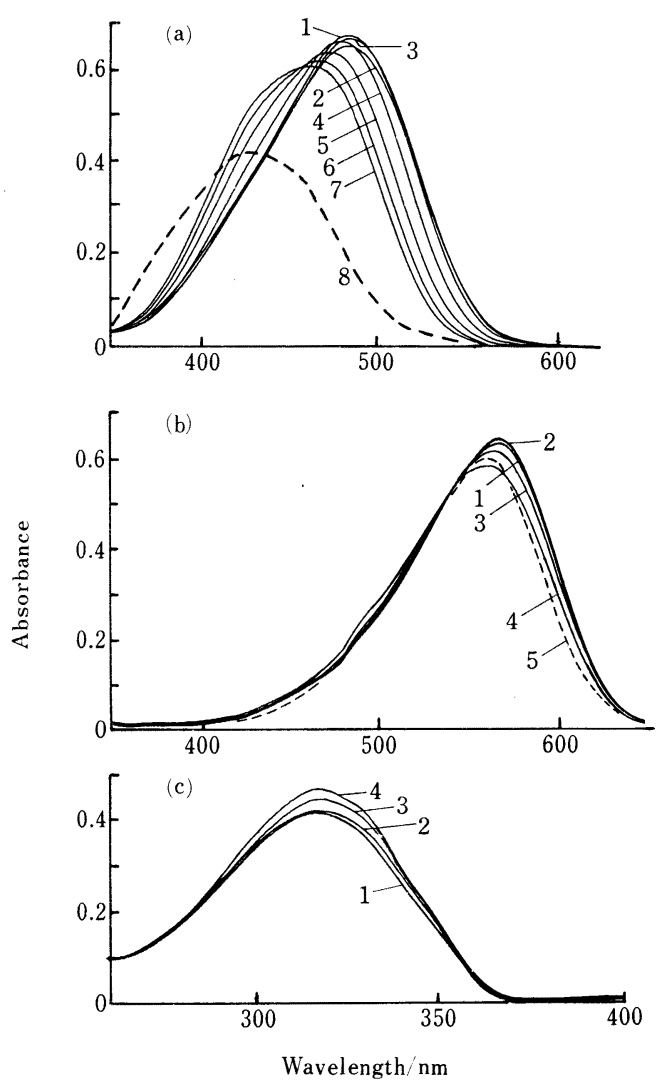

Fig. 3 Typical absortion spectra

a) PO $\left(2.0 \times 10^{-5} \mathrm{M}\right)$. Alcohol $(\mathrm{v} / \mathrm{v} \%): 1,0$; 2,$10 ; 3,20 ; 4,30 ; 5,40 ; 6,50 ; 7,60 ; 8,0$ (solvent, $\left.\mathrm{CHCl}_{3}\right)$. b) MEP $\left(1.0 \times 10^{-5} \mathrm{M}\right)$. Alcohol $(\mathrm{v} / \mathrm{v} \%): 1,0 ; 2,20 ; 3,40 ; 4,60 ; 5,0$ (solvent, $\left.\mathrm{CHCl}_{3}\right)$. c) AD-TMA $\left(3.0 \times 10^{-5} \mathrm{M}\right)$. Alcohol (v/v\%) : 1, 0; 2, 20;3, 40;4, 60
II では吸光度の娍少する $570 \mathrm{~nm}$, Type III では吸光度 の増加する $315 \mathrm{~nm}$ における值を示している. いずれも エタノール $0 \sim 20 \%(\mathrm{v} / \mathrm{v})$ 程度では吸光度の変化は小さ い. エタノール $20 \%(\mathrm{v} / \mathrm{v})$ 以上における吸光度の変化 量の大きさの順は, Type I > Type II > Type III となっ ている.

Type 1 では, Fig. 5 に示すように, (A)と (B)の極限 構造式が考えられる. 誘電率の大きい水溶液中では $(\mathrm{A})$ の寄与が大きく, アルコール量の増加と共に $(\mathrm{A})$ の寄与

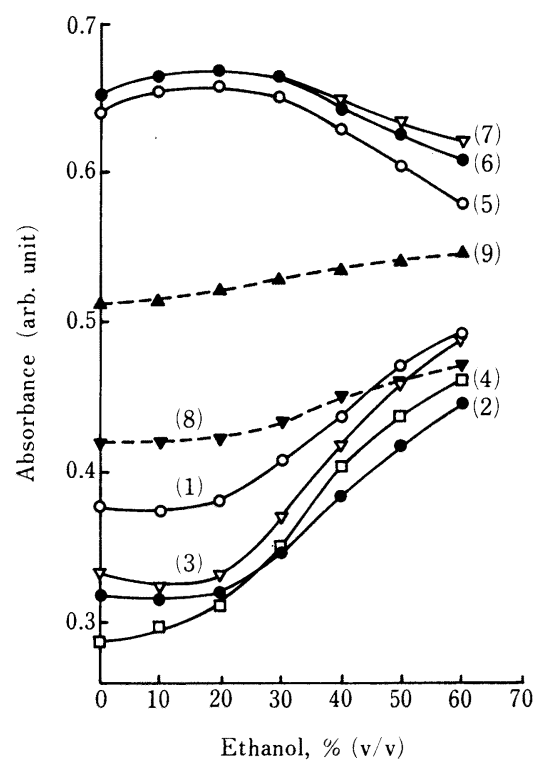

Fig. 4 Effect of alcohol concentration

Type I $\left(2.0 \times 10^{-5} \mathrm{M}, 420 \mathrm{~nm}\right): 1, \mathrm{MO} ; 2$, EO; 3 , PO; 4, BO. Type II $\left(1.0 \times 10^{-5} \mathrm{M}\right.$, $570 \mathrm{~nm}): 5$, MEP; 6 , EEP; 7, PEP. Type III $\left(3.0 \times 10^{-5} \mathrm{M}, 315 \mathrm{~nm}\right): 8, \mathrm{AD}-\mathrm{TMA} ; 9, \mathrm{NO}_{2}{ }^{-}$ AD-TMA

A

B

Type I<smiles></smiles><smiles>[R12]c1ccc(N=Nc2ccc(S(=O)(=O)O)cc2)cc1</smiles>

Type II<smiles>[R][n+]1ccc(N=Nc2ccc(N=[Y10])cc2)cc1</smiles><smiles>[R]N1C=CC(NN=C2C=CC([N+]#[R12])C=C2)C=C1</smiles>

Type III<smiles>[X]c1ccc(N=Nc2ccc(N(C)C)cc2)cc1</smiles>

Fig. 5 Resonance forms of azo dyes 
が減少し, (B)の寄与が増し, 次第にブルーシフトし, クロロホルム中での吸収曲線に近づいていく.

Type II では $(\mathrm{A}),(\mathrm{B})$ いすれにおいても 1 個の陽電 荷をもつ構造しかとれないが, モル吸光係数から考えて (B)の寄与が大部分であろうと考えられる.

Type III では陽電荷は第四級アンモニウムの窒素上 に局在しており，吸収波長のシフトはほとんどないもの と考えられる. 又, 吸収極大波長は I III の中で最も 短波長側にあり，モル吸光係数も小さい.

以上のことから, Type I の試薬の吸収変化を利用す れば高感度定量が可能と分かる.

\section{$3 \cdot 2$ 吸光度変化に及ぼす各種有譏溶媒の影䍂}

Fig. 6 にMO を用いた場合 $420 \mathrm{~nm}$ における吸光度 変化を示す.アルコール類では, 吸光度変化量はアルキ ル炭素数の大きいものほど大きいことが分かる．これは 疎水性のものほどその寄与が大きいことを示し, 疎水性 の大きいアルコールほど疎水性の染料イオンの周りに集 まりやすいためと考えられる.この現象は, Fig. 4 の Type I の染料における吸光度変化の大きさの順，すな わちジアルキルアミノ基のアルキル鎖の長いもの（疎水 性の大きいもの）ほよ゙吸光度, 変化は大きいことと一致 している.いずれのアルコールにおいても $0 \sim 10 \%$

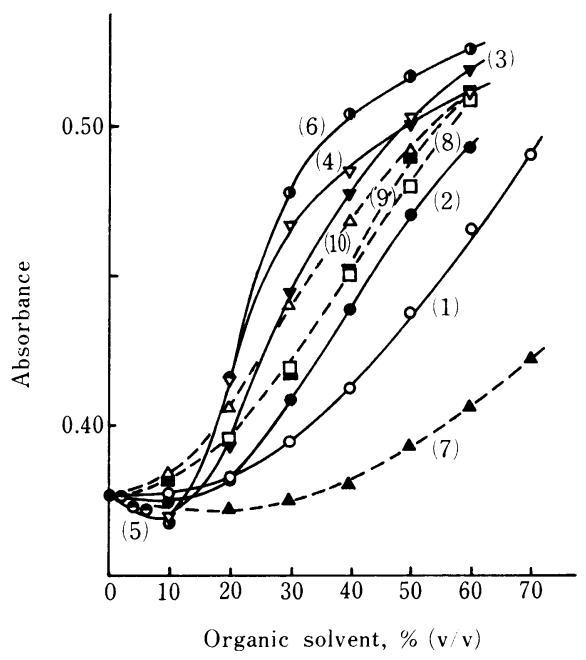

Fig. 6 Effect of amount of organic solvent on the absorbance of MO at $420 \mathrm{~nm}$

1:methanol; 2 :ethanol; $3: 1$-propanol; 4 : 2-propanol; 5:1-butanol; 6:t-butanol; $7:$ ethyleneglycol; $8:$ dioxane; $9:$ acetone; $10:$ acetonitrile $(\mathrm{v} / \mathrm{v})$ 程度では吸光度の増加分は負か又はほとんどな い。これは水の水款構造の中へ水素結合により取り込ま れアルコールー水の安定な水化物を形成しているためと 考えられる. 一方, 水素結合しがたいジオキサン, アセ トン, アセトニトリルなどでは, $10 \%(\mathrm{v} / \mathrm{v})$ では吸光度 増加分はアルコール類よりも大きいが，30\%(v/v) 程度 では2-プロパノールよりも寄与は小さい.

\section{3・3 アルコールの吸光光度法}

Fig. 6 とほぼ同様な関係図が他の Type I の染料につ いても描ける．Fig. 4 に示すようにブチルオレンジで吸 光度変化は最も大きいが, 界面活性能があり, 振り混ぜ により泡立ち，又 PTFEチューブなどに付着しやす い.このため, プロピルオレンジを用いて検討した. 例 えば，エタノール定量の場合，0〜20\%(v/v) では吸光 度変化は非常に小さい，従って，あらかじめ， $20 \%$ (v/v) 相当分のエ夕ノールを常に加えるようにした。す なわち，検量線はFig. 4 の $20 \%(\mathrm{v} / \mathrm{v})$ から始まること になり, 試料中のアルコールが最終濃度として 0 〜 $30 \%$ ( v/v) の範井でほぼ直線となる。

本法における吸光度変化は，Fig. 6 に示すようにアル コール類又はその他の有機溶媒類において感度の差異は あるが選択性はほとんどない，従って，単一アルコール 試料又は HPLC などのポストカラム発色法として使用 可能であろう。

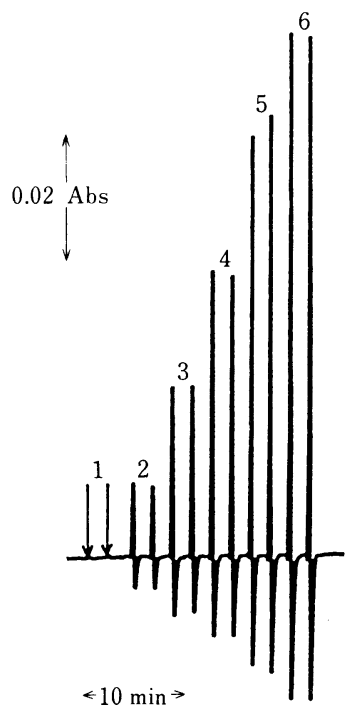

Fig. 7 Flow signals for ethanol determination Ethanol (v/v\%) : 1, 0; 2, 5; 3, 10;4, 15; 5, 20; 6,25 . PO : $10^{-3} \mathrm{M} ; \mathrm{pH}, 6.7 ; \lambda=420 \mathrm{~nm}$ 


\section{$3 \cdot 4$ エタノールの FIA 法}

バッチ式マニュアル法の試薬組成 (最終濃度) の倍の 濃度の溶液を試薬流れとして用いた。試料はキャリヤ一 流れに注入した.フローシグナルの例を Fig. 7 に示 す.ピーク高さを用いる検量線は直線関係とはならない が, 数パーセント程度のアルコールの定量も可能であ る.

終わりに, $N, N, N$-Trimethyl-p-phenylazoanilinium chloride 及びそのニトロ誘導体を御恵与いただいた岡山大学理学 部山本峻三博士に深謝いたします。

\section{$\left(\begin{array}{l}1989 \text { 年 } 6 \text { 月, 第 } 50 \text { 回分析化学討論会 } \\ \text { において一部発表 }\end{array}\right.$}

\section{文献}

1) R. L. Letsinger, T. J. Savereide : J. Am. Chem. Soc., 84, 114, 3122 (1962); C. G. Overberger, I. S. Klaus : ibid., 87, 3380 (1965).

2) F. Cramer, W. Saenger, H.-Ch. Spatz:J. Am. Chem. Soc., 89, 14 (1967).

3) 山本大二郎, 安部卓郎: 明治大学農学部報告, 78 号, 65 (1988).

4) 細井康宏, 本水昌二: 分析化学, 37, 301 (1988).

5）岩知道正, 田尻政直, 桐栄恭二: 分析化学, 34, 579 (1985).

6) S. Motomizu, M. Onoda, M. Oshima, T. Iwachido: Analyst (London), 113, 743 (1988).

7) L. F. Fieser: "Experiments in Organic Chemistry", (1957), (D. C. Health, Boston).

8) S. Motomizu, Y. Hazaki, M. Oshima, K. Tôei : Anal. Sci., 3, 265 (1987).

9) S. Yamamoto, N. Nishimura, S. Hasegawa : Bull. Chem. Soc. Jpn., 46, 194 (1973).

$$
\text { is }
$$

Color change behavior of water soluble azo-dye ions in a water-organic solvent mixed medium and its application to a spectrophotometric method for the determination of ethanol. Shoji Moтомге, Yasuhiro Hosor and Mitsuko Oshima (Department of Chemis- try, Faculty of Science, Okayama University, 3-1-1, Tsushimanaka, Okayama-shi, Okayama 700)

Solvent effects on the absorption spectra of water soluble azo-dye ions were investigated. Three types of azo-dyes (Type I, II and III) were used : Type I consists of 4-(4-dialkylaminophenylazo)benzene sulfonate ions (alkyl : methyl, ethyl, propyl and butyl groups), Type II, of 1-alkyl-4-(4-diethylaminophenylazo) pyridinium ions (alkyl : methyl, ethyl and propyl groups) and Type III, of $N, N, N$-trimethyl-p-phenylazoanilinium ion and its nitro derivative. Of these three types, the Type I dyes showed the most remarkable change in absorption spectrum. The absorption maximum wavelength decreased with increasing alcohol content: the more hydrophilic the dye ion and the alcohol, the greater was the blue shift of the absorption spectrum. This remarkable blue shift is attributed to a change in the contributions of the following resonance forms :

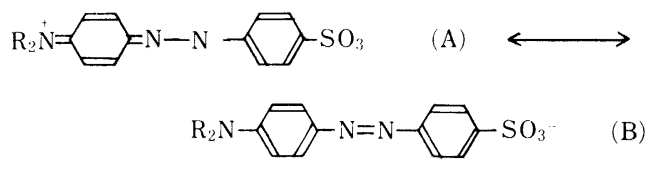

With an increasing alcohol concentration or hydrophobicity around the dye ion, the contribution of the cationic form (A) decreases. By measuring the change in Propyl Orange absorbance at $420 \mathrm{~nm}$, ethanol can be determined. The absorptiometric method of ethanol determination with Propyl Orange was applied to the flow injection procedure.

(Received November 22, 1989)

\section{Keyword phrases}

color change behavior of water-soluble dyes; anionic and cationic azo-dyes; spectrophotometry of alcohol; FIA. 